\title{
Daño pulmonar grave en vapeadores
}

\author{
Severe lung damage in vapers
Ireri Thirión-Romero,* Sebastián Rodríguez-Llamazares,* Kevin Terán-De la Sancha,* Miguel González-Woge,* Rogelio Pérez-Padilla*

*Instituto Nacional de Enfermedades Respiratorias Ismael Cosío Villegas, Ciudad de México, México.

Palabras clave: Cigarrillo electrónico, vapeadores, neumonía lipoídica, falla respiratoria aguda.

Keywords: Electronic cigarette, vapers, lipoid pneumonia, acute respiratory failure.

Todas las llamadas de atención hacia los riesgos de inhalar los cigarrillos electrónicos, vapear en términos coloquiales, han sido minimizadas y desatendidas, a pesar de haberse emitido alertas por sociedades respiratorias mundiales. ${ }^{1,2}$ Por el contrario, las ventas de los dispositivos han sido exponenciales, a pesar de ser ilegales en varios países como México, llegando incluso a existir sitios específicos para realizar esta actividad.

Los riesgos a la salud pública emanan primordialmente del esperado incremento en adictos a la nicotina, que pasan a fumar cigarrillos normales en forma única o combinada; sin embargo, también están aquéllos generados por los efectos irritantes en el pulmón, aunados a los debidos al mal funcionamiento de las baterías y al calentamiento del dispositivo.

Recientemente, se ha notificado a través del Centro de Control de Enfermedades y Prevención (por sus siglas en inglés (DC) así como por la Administración de Fármacos y Alimentos (por sus siglas en inglés FDA) sobre 2,506 pacientes hospitalizados hasta el 17 de Diciembre del 2019, asociada al uso de cigarro electrónico, la mayoría de ellos adolescentes y adultos jóvenes. ${ }^{3-9}$

Los cigarros electrónicos son dispositivos que generan un aerosol (erróneamente llamado vapor) a través del calentamiento de un líquido que contiene nicotina, glicerina,

Correspondencia:

\section{Dr. Rogelio Pérez-Padilla}

Instituto Nacional de Enfermedades Respiratorias Ismael Cosío

Villegas, Ciudad de México, México.

Correo electrónico: perezpad@gmail.com

Trabajo recibido: 10-IX-2019; aceptado: 25-IX-2019. propilenglicol y saborizantes. Se han encontrado más de 80 componentes en el aerosol inhalado de manera habitual, entre ellos formaldehído, compuestos orgánicos volátiles, hidrocarburos policíclicos, nitrosaminas y metales (cromo, cadmio, zinc, níquel), estos últimos productos frecuentes del calentamiento por pirólisis o procedentes de la batería. El aerosol alcanza ampliamente al sistema respiratorio, tanto en vías aéreas de conducción como en zonas alveolares, debido al pequeño tamaño de las partículas generadas (100-160 nm). ${ }^{10,11}$ En las mezclas originales se han encontrado variados tóxicos como el acetaldehído, diacetilo o 2-3 butanodiona, dihidroxiacetona, entre otros, todos ellos asociados con efectos carcinogénicos y de lesión pulmonar. En general estas sustancias se encuentran en concentraciones bajas y pese a que se han reportado reacciones de inflamación o estrés oxidativo, la generación de síntomas y problemas de salud es limitada: se ha descrito un incremento de síntomas respiratorios en sujetos con pulmones sanos, un empeoramiento de síntomas respiratorios en pacientes con asma, enfermedad pulmonar obstructiva crónica (EPOC) y fibrosis quística, así como un incremento en la virulencia de microorganismos como Staphylococcus aureus, y un aumento en la tasa de infecciones por virus (rinovirus). ${ }^{11,12}$

En los casos actuales, los síntomas reportados han sido disnea progresiva en días a semanas, tos seca, dolor pleurítico y otras manifestaciones clínicas generales como fatiga, adinamia y fiebre. En algunos casos, los trastornos gastrointestinales como vómito y diarrea preceden a los síntomas respiratorios. Se ha documentado la presencia de leucocitosis sin identificación de agente infeccioso así como opacidades bilaterales pulmonares usualmente en patrón radiológico de vidrio deslustrado o de árbol en gemación. ${ }^{9}$ Varios de estos pacientes visitaron servicios de urgencias en varias ocasiones antes de hospitalizarse. En $31 \%$ de los pacientes se documentó hipoxemia y más de $50 \%$ de los pacientes requirieron ingreso a terapia intensiva 
por progresión del cuadro a falla respiratoria aguda.,5,13 En los lavados bronquioloalveolares se ha identificado la presencia de macrófagos con inclusiones lipídicas ${ }^{8,9}$ Como los que se describen en la neumonía lipoidea.

La mayoría de los pacientes recibieron esteroides sistémicos, con lo que se observó mejoría hasta en $65 \%$ de ellos; ${ }^{13}$ hasta el momento se han reportado 54 decesos en EE.UU., varios en Latinoamérica, incluyendo uno en México, asociados al consumo de cigarro electrónico y falla respiratoria. ${ }^{5}$ Esta presentación implica un daño grave y rápido que no se había considerado en la gama de daños que pudiera causar el cigarrillo electrónico.

En la mayoría de los casos descritos se ha encontrado no sólo el uso de cigarro electrónico con el líquido tradicional, sino también su uso para la administración de tetrahidrocannabinol (THC), ${ }^{6}$ el cual inclusive se administra a través de extractos oleosos caseros ${ }^{10,11}$ con un potencial mayor de contaminación y en mezclas poco propicias para su inhalación. Ello por lo regular genera una neumonía lipoidea, pero puede producir también daño alveolar difuso; asimismo es probable que se puedan aerosolizar otros tóxicos como los que se podrían generar por pirólisis y en un momento dado bacterias o productos bacterianos. En uno de los reportes recientes no se identificó una sola sustancia en particular como generadora del daño. ${ }^{8}$

Es imperativo que se concrete de manera urgente una regulación estricta de estos dispositivos como cualquier otro producto de tabaco, ${ }^{1,14}$ de modo que cada uno de sus componentes se haga explícito, para así lograr también que los equipos y líquidos para inhalar tengan un control de calidad adecuado. Más aún, dichos productos deberían estar legalmente sujetos a las mismas medidas utilizadas para desincentivar el consumo de sus predecesores: desde impuestos, leyendas precautorias específicas e imágenes de advertencia en sus empaques.

En definitiva se irá aclarando el origen de este brote, pero por lo pronto alertamos sobre el potencial de los dispositivos electrónicos de generar daño pulmonar grave a corto plazo.

\section{REFERENCIAS}

1. ALAT. Declaración de las Sociedades Científicas Neumológicas iberolatino-americanas sobre los dispositivos electrónicos de liberación de nicotina. 2019.

2. Jenssen BP, Walley SC; SECTION ON TOBACCO CONTROL. E-Cigarettes and similar devices. Pediatrics 2019;143(2). pii: e20183652. doi: 10.1542/peds.2018-3652.

3. Statement from CDC Director Robert R. Redfield, M.D., and Acting FDA Commissioner Ned Sharpless, M.D., on federal and state collaboration to investigate respiratory illnesses reported after use of e-cigarette products. 2019.

4. HHS.gov. HHS Secretary Azar Statement on IIInesses Associated with E-Cigarettes. 2019.

5. Severe Pulmonary Disease Associated with Using E-Cigarette Products. 2019. Disponible en: https://www.cdc.gov/tobacco/ basic_information/e-cigarettes/severe-lung-disease.html

6. E-Cigarette products: Safety communication - Due to the incidents of severe respiratory disease associated with use of an E-Cigarette product. 2019. Disponible en: https://www.fda.gov/safety/medwatchsafety-alerts-human-medical-products/e-cigarette-productssafety-communication-due-incidents-severe-respiratory-diseaseassociated-use-e.

7. Shmerling RH. Can vaping damage your lungs? What we do (and don't) know. 2019. Disponible en: https://www.health.harvard. edu/blog/can-vaping-damage-your-lungs-what-we-do-and-dontknow-2019090417734.

8. Schier JG, Meiman JG, Layden J, Mikosz CA, VanFrank B, King $\mathrm{BA}$, et al. Severe pulmonary disease associated with electroniccigarette-product use -interim guidance. MMWR Morb Mortal Wkly Rep [Internet]. 2019 [cited 2019 Sep 9];68(36). Available from: http://www.cdc.gov/mmwr/volumes/68/wr/mm6836e2. $\mathrm{htm}$ ?s_cid=mm6836e2_w

9. Davidson K, Brancato A, Heetderks P, Mansour W, Matheis E, Nario $\mathrm{M}$, et al. Outbreak of electronic-cigarette-associated acute lipoid pneumonia - North Carolina, July-August 2019. MMWR Morb Mortal Wkly Rep [Internet]. 2019 [cited 2019 Sep 9];68(36). Available from: http://www.cdc.gov/mmwr/volumes/68/wr/mm6836e1. $\mathrm{htm}$ ?s_cid=mm6836e1_w

10. Disease Control C, Center for Chronic Disease Prevention N, Promotion H, on Smoking O. Department of Health U, Services $\mathrm{H}$, for Disease Control C, Center for Chronic Disease Prevention $\mathrm{N}$, Promotion $\mathrm{H}$, on Smoking $\mathrm{O}$. E-cigarette use among youth and young adults: a report of the surgeon general. 2016. Available from: https://www.cdc.gov/tobacco/data_statistics/sgr/e-cigarettes/ pdfs/2016_sgr_entire_report_508.pdf.

11. Chun LF, Moazed F, Calfee CS, Matthay MA, Gotts JE. Pulmonary toxicity of e-cigarettes. Am J Physiol Lung Cell Mol Physiol 2017;313(2):L193-L206. doi: 10.1152/ajplung.00071.2017.

12. Kaur G, Pinkston R, Mclemore B, Dorsey WC, Batra S. Immunological and toxicological risk assessment of e-cigarettes. Eur Respir Rev 2018:27(147):pii170119. doi: 10.1183/16000617.0119-2017.

13. Layden JE, Ghinai I, Pray I, Kimball A, Layer M, Tenforde M, et al. Pulmonary illness related to E-Cigarette use in Illinois and Wisconsin -Preliminary report. N Engl J Med 2019. doi: 10.1056/ NEJMoa1911614.

14. Thirión-Romero I, Pérez-Padilla R, Zabert G, Barrientos-Gutiérrez I. Respiratory impact of electronic cigarettes and Low-Risk tobacco. Rev Invest Clin [Internet]. 2019 [cited 2019 Sep 3];71(1). Available from: http://www.clinicalandtranslationalinvestigation.com/frame_esp. php?id=199

Conflicto de intereses: Los autores declaran no tener conflicto de intereses. 